\title{
Development of highly functionalized ceramic biomaterials
}

\author{
Chikara OHTSUKI ${ }^{\dagger}$ \\ Department of Crystalline Materials Science, Graduate School of Engineering, Nagoya University, \\ Furo-cho, Chikusa-ku, Nagoya 464-8603, Japan
}

\begin{abstract}
Ceramic biomaterials have been used clinically for repairing bony defects due to their biological affinity to living bone. Among ceramic biomaterials, bioactive ceramics directly bond to living bone. The bonding mechanism of bioactive ceramics to living bone provides a unique strategy in the development of novel biomaterials with high functionality. The mechanism of bonebonding has been clarified through observation of interfaces between artificial materials and living bones as well as investigation of structural changes of the materials in solutions mimicking in vivo conditions. A simulated body fluid (SBF) that has similar concentrations of inorganic ions has been used to estimate surface structural changes of implanted materials in bony defects. Bone-like apatite deposition on the surface of implants is an important event to achieve bone-bonding with bioactive ceramics. Thus, it is important to control the reaction of such materials with body fluid during the development of novel biomaterials. Based on a fundamental understanding of the reactions of ceramic materials in SBF, novel types of biomaterials have been designed, such as surface-modified titanium metal, organic-inorganic hybrids, biomimetic composites, bioabsorbable materials, and calcium phosphates with designed morphology. In this review, the development of bioactive materials is described through a fundamental understanding of the calcification mechanisms of bioactive ceramics in SBF.
\end{abstract}

(C)2013 The Ceramic Society of Japan. All rights reserved.

Key-words : Ceramic biomaterials, Calcium phosphates, Bioactive materials, Organic-inorganic hybrids, Simulated body fluid, Biomimetics

[Received October 16, 2012; Accepted December 3, 2012]

\section{Introduction}

Ceramic materials have been used clinically in orthopedics and dentistry. Ceramic biomaterials, generally called bioceramics, are important to support quality of life by recovering the functions of hard tissue, i.e. bone, because bones support our bodies and enable us to perform various motions. Artificial bone is defined as an artificial material able to fill defects in bony tissues. Artificial bone requires high affinity to living bone to achieve tight bonding after implantation in bony tissues. Some types of ceramic biomaterials show high biological affinity to living bone and bond directly to it. On application of artificial bone, the ceramics that show this unique physiological property are known as bioactive materials. The direct bonding of artificial materials to living bone is a typical property to express bioactivity of artificial materials, while the term of bioactive materials generally includes materials that show biological activity after exposure to the body and its system. In the view of development of ceramic biomaterials, the capability to make direct bonds to living bone after implantation in bony defects is distinct requirements, and the capability is often called bioactivity.

In the field of ceramic biomaterials, bioactive material was discovered by Hench et al. They reported that certain compositions of glass in $\mathrm{Na}_{2} \mathrm{O}-\mathrm{CaO}-\mathrm{SiO}_{2}-\mathrm{P}_{2} \mathrm{O}_{5}$ system showed direct bonding properties to living bone (bone-bonding properties) after implantation in the bony tissue. ${ }^{1)}$ Since the discovery of the bioactive glass showing bone-bonding properties, several types of ceramics have been developed for artificial bones. ${ }^{2)}$ Although bioactive ceramics have shown high biological affinity, their mechanical properties have not been sufficient to substitute loadbearing parts, namely large parts of cortical bone. Especially, the

\rceil Corresponding author: C. Ohtsuki; E-mail: ohtsuki@apchem. nagoya-u.ac.jp elastic moduli of ceramic biomaterials are generally too high for substitution of natural bone, because ceramic biomaterials are mere ceramics, while natural bone is an organic-inorganic composite composed of hydroxyapatite [HAp, $\mathrm{Ca}_{10}\left(\mathrm{PO}_{4}\right)_{6}(\mathrm{OH})_{2}$ as stoichiometric composition] and collagen. Biological apatites differ from stoichiometric HAp, and are often simply called "apatite".

Fundamental understanding of the reactions of bioactive ceramics in body fluid allows the development of biomaterials for bone repair as well as biomimetic processing of designed composites. In this paper, novel designs for bone defect-repairing biomaterials are reviewed through an understanding of the surface reactions of bioactive ceramics. In addition, designed materials and fabrication processes, which are inspired by the reactions of bioactive ceramics in body fluid, are also discussed.

\section{Bonding mechanisms of bioactive ceramics to bone}

HAp formation has been observed on the surfaces of bioactive glasses and glass-ceramics after their implantation in bony defects. ${ }^{3)-5)}$ Artificial materials bond to bone through this HAp layer. Similar type of HAp layer is formed on bioactive glasses and glass-ceramics when they are soaked in a type of simulated body fluid proposed by Kokubo and his colleagues, described below. HAp layer formed on the bioactive glasses and glassceramics after exposure to the simulated body fluid was characterized by small crystallites, large amounts of defects in its structure and incorporation of carbonate ion in compositions. The characteristics of the HAp crystals formed on the bioactive glasses and glass-ceramics are similar to those composed of bone mineral. Hence, the HAp is described as "bone-like apatite". Thus the characters of the formed "bone-like apatite" is important on establish the bonding to living bone. Figure 1 shows a schematic illustration of the bonding process of artificial materials to bone. ${ }^{6}$ In the first step, a bone-like apatite layer 


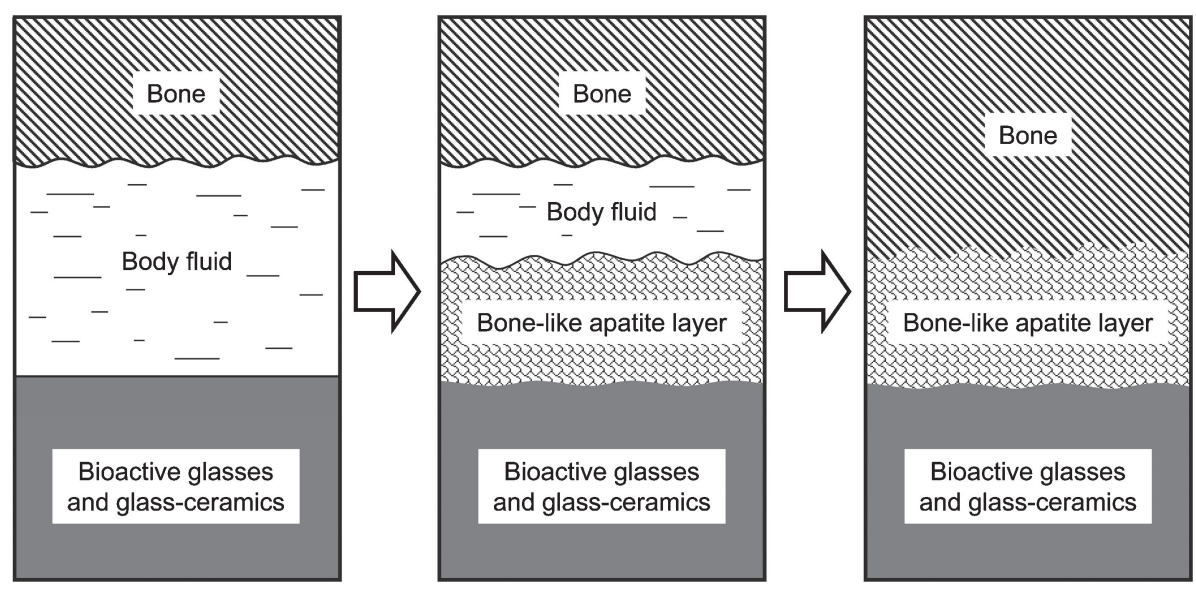

Fig. 1. Schematic illustration of the bone-bonding process of bioactive glasses and glass-ceramics to living bone. In a bony defect, bioactive materials bond to bone after being covered by bone-like apatite. ${ }^{\text {) }}$

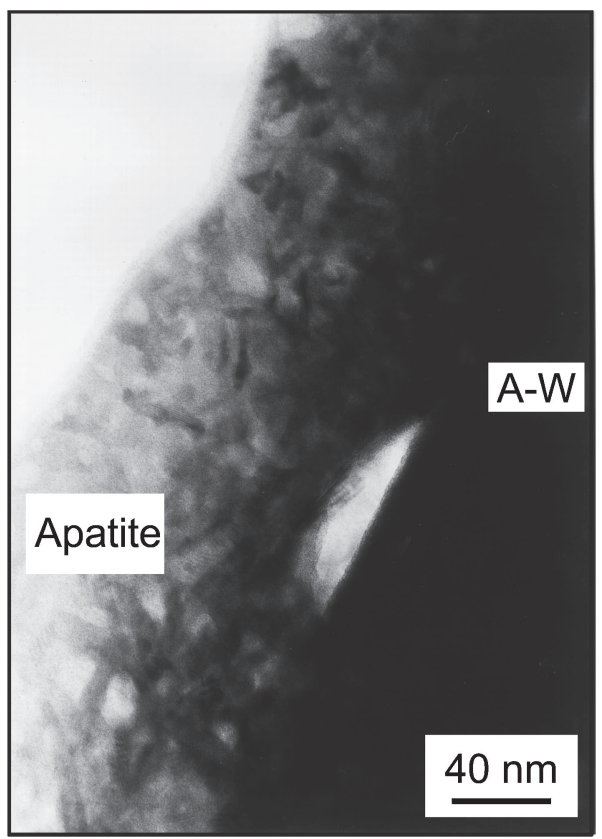

Fig. 2. Transmission electron microscopy image of bone-like apatite (Apatite) formed on glass ceramic A-W (A-W) after soaking in SBF for 30 days. ${ }^{8)}$

forms on the bioactive ceramic. In the second step, bone tissues grow on the bone-like apatite layer. Bone-like apatite formation is not observed on non-bioactive glasses and glass-ceramics of similar compositions and phases. To evaluate the apatite deposition potential of materials, Kokubo and his colleagues developed a type of simulated body fluid, that is often abbreviated as SBF, with similar concentrations of inorganic ions to those found in human blood plasma. ${ }^{7}$ The $\mathrm{pH}$ of SBF is adjusted to physiological conditions, e.g. 7.25 or 7.40 , with appropriate amounts of trishydroxymethyl aminomethane and hydrochloric acid. Figure 2 shows a layer of bone-like apatite formed on bioactive glass-ceramic $\mathrm{A}-\mathrm{W}$, which contains oxyfluoroapatite and $\beta$ wollastonite, after soaking in SBF for 30 days. ${ }^{8)}$ The formed layer consisted of bone-like apatite with similar crystallinity and composition to that in human bone. The chemical and structural characteristics of this layer allowed direct contact to living bone tissues. These findings imply that formation of a bone-like apatite layer on the material surface after implantation is required for

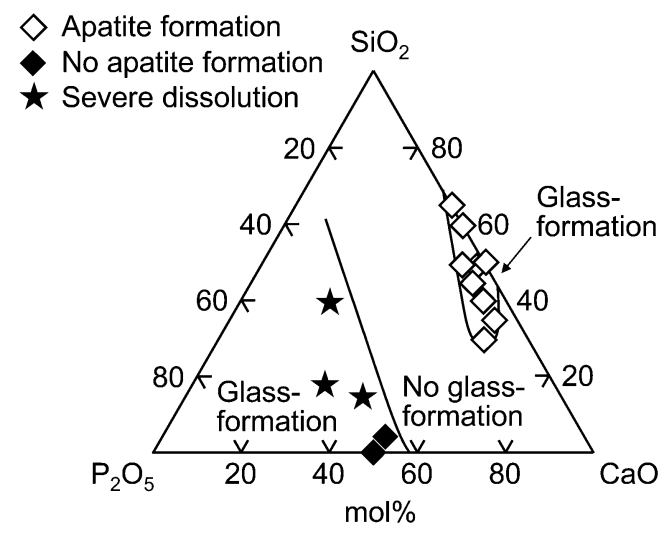

Fig. 3. Compositional dependence of apatite-forming ability of $\mathrm{CaO}-$ $\mathrm{SiO}_{2}-\mathrm{P}_{2} \mathrm{O}_{5}$ glasses in $\mathrm{SBF}$ (soaking period: 30 days). ${ }^{9}$ )

bonding artificial materials to bones.

Knowing that the deposition of bone-like apatite is needed to achieve direct bonding to living bone, the compositional dependence of bone-like apatite formation on ceramics provides an important strategy for the design of novel bioactive materials with bone-bonding properties. Compositional dependence of apatite-forming ability in SBF has been reported for glasses of various compositions, ${ }^{9), 10)}$ because glass allows wide compositional changes while maintaining a homogeneous structure. Figure 3 shows the compositional dependence of the apatiteforming ability of glasses in the $\mathrm{CaO}-\mathrm{SiO}_{2}-\mathrm{P}_{2} \mathrm{O}_{5}$ system. ${ }^{9)}$ The apatite-forming ability of the glasses in $\mathrm{SBF}$ was higher for those in compositional regions rich in $\mathrm{CaO}$ and $\mathrm{SiO}_{2}$ than those in compositional regions rich in $\mathrm{CaO}$ and $\mathrm{P}_{2} \mathrm{O}_{5}$. Apatite formation was especially observed on glasses in the binary system $\mathrm{CaO}-$ $\mathrm{SiO}_{2}$. This indicated that calcium silicate ceramics have sufficient potential to act as essential compositions for the production of bioactive materials with high biological affinity to living bone. The formation of apatite on $\mathrm{CaO}-\mathrm{SiO}_{2}$ glass was found to be triggered by the release of calcium ions from the glass, and by the induction of heterogeneous nucleation on a silica hydrogel layer formed by hydration of the glass. ${ }^{11)}$ The release of calcium ions from glasses increases the degree of HAp supersaturation in $\mathrm{SBF}$. The silica hydrogel, rich in silanol $(\mathrm{Si}-\mathrm{OH})$ groups which play a role in producing favored sites for apatite nucleation, induces heterogeneous nucleation of the apatite. This induction of apatite nucleation has been observed on silica hydrogel after 
soaking in SBF. ${ }^{12)}$ Ti-OH and carboxyl $(-\mathrm{COOH})$ groups have also been reported to induce apatite nucleation in $\mathrm{SBF}{ }^{13), 14)}$ Therefore, there are two main parameters determining apatite deposition on a substrate after implantation in bony defects; the release of chemical species which increase the degree of HAp supersaturation in the surrounding fluid, and the induction of heterogeneous nucleation of apatite by certain types of functional groups.

Hybridization of these two factors may provide novel designs for materials with bone-bonding properties. Namely, surface treatment of metallic materials applied to provide bioactivity, and organic modification applied to the $\mathrm{CaO}-\mathrm{SiO}_{2}$ binary system to create bioactive organic-inorganic hybrids.

\section{Providing bone-bonding properties to metallic materials}

Titanium and its alloys are now widely used in orthopedics and dentistry for example in artificial hip joint stems and tooth roots, respectively. Coating with HAp is a well-known process to provide bioactivity to titanium-based materials, i.e. providing bone-bonding properties. In contrast, understanding the mechanism of apatite deposition on bioactive ceramics leads to a possible method for fabricating bioactive titanium-based materials through surface chemical treatments. Surface treatment of titanium substrates with sodium hydroxide $(\mathrm{NaOH})$ solution followed by heat treatment has been found to result in an apatiteforming ability through formation of a sodium titanate gradient structure. ${ }^{15)}$ The sodium titanate layer reacts with body fluid to increase the $\mathrm{pH}$ as well as formation of $\mathrm{Ti}-\mathrm{OH}$ groups. This reaction may induce heterogeneous nucleation of a bone-like apatite layer on the surface of titanium substrates after their implantation in the body. Simple chemical treatment of titanium substrate with $30 \mathrm{vol} \% \mathrm{H}_{2} \mathrm{O}_{2}$ solution containing $5 \mathrm{~mol} \cdot \mathrm{m}^{-3}$ tantalum chloride $\left(\mathrm{TaCl}_{5}\right)$ also improved apatite formation ability in SBF. ${ }^{16)}$ An enhanced bonding property was observed in vivo for titanium substrate treated by $\mathrm{H}_{2} \mathrm{O}_{2}$ solution containing $\mathrm{TaCl}_{5}{ }^{17)}$ Apatite formation was induced by formation of a suitable titania hydrogel layer after the treatment.

Furthermore, the modification of surface topography and oxidation of titanium-based materials has been found to enhance their apatite-forming ability. A specific spatial gap between thermally oxidized titanium substrate and polytetrafluoroethylene substrate enhances the formation of bone-like apatite in SBF. ${ }^{18)}$ The apatite-forming ability of thermally oxidized titanium substrate is dependent on the width of this spatial gap. According to investigation of the relationship between gap width and depth

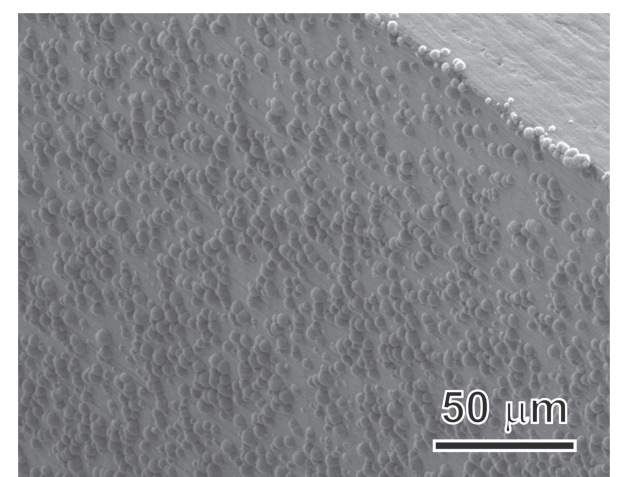

Fig. 4. Scanning electron microscopy image of bone-like apatite particles formed in macro-grooves of a pure titanium specimen thermally oxidized at $400^{\circ} \mathrm{C}$ after soaking in SBF for 7 days. ${ }^{19}$ ) and apatite-forming ability for a grooved titanium substrate heat treated at $400^{\circ} \mathrm{C}$, heat-treated titanium metal with gaps ranging $200-800 \mu \mathrm{m}$ in width and $200-1000 \mu \mathrm{m}$ in depth showed high apatite-forming ability in SBF. ${ }^{19)}$ Figure 4 shows apatite formed in the groove of a titanium substrate after exposure to SBF. Thus, spatial design provides a new concept for conferring bioactivity to titanium-based materials simply by machining and thermal oxidization.

\section{Development of bioactive organic-inorganic hybrids}

Organic modification of the $\mathrm{CaO}-\mathrm{SiO}_{2}$ binary system can provide bone-bonding properties to various materials as well as functionalities derived from organic substances. Sol-gel processing using organosilanes and organic substances allows the production of organically modified silicates. Incorporation of a calcium salt in these organically modified silicates provides the resultant materials with an apatite-forming ability in SBF, and thus the potential for bone-bonding. Such designed organicinorganic hybrids exhibiting formation of bone-like apatite on their surfaces in SBF were first reported for polydimethylsiloxane (PDMS) $-\mathrm{CaO}-\mathrm{SiO}_{2}$ systems, ${ }^{20)}$ followed by those of PDMS$\mathrm{CaO}-\mathrm{SiO}_{2}-\mathrm{TiO}_{2}{ }^{21)}$ and poly(tetramethylene oxide) $-\mathrm{CaO}-\mathrm{SiO}_{2}{ }^{22}$ )

The concept of bioactive organic-inorganic hybrids can be extended to polymer matrices modified with $\mathrm{Si}-\mathrm{OH}$ groups and calcium salts. Bioactive organic-inorganic hybrids were prepared using methacryloxypropyltrimethoxysilane (MPS), 2-hydroxyethylmethacrylate (HEMA), and calcium salt. ${ }^{23)}$ MPS provides $\mathrm{Si}-\mathrm{OH}$ groups after hydrolysis, while HEMA makes a hydrophilic polymer matrix in the hybrid. A homogeneous transparent gel was obtained for the composition MPS:HEMA $=0.1: 0.9$ (molar ratio) with incorporated calcium chloride $\left(\mathrm{CaCl}_{2}\right)$, the resulting hybrid formed a bone-like apatite layer within 7 days in SBF. Modification of other organic polymers, such as polysaccharides and poly(amino acids), with $\mathrm{Si}-\mathrm{OH}$ groups and calcium salts successfully produced bioactive organic-inorganic hybrids using the same concepts. ${ }^{24)-26)}$

Chemical modification with $\mathrm{Si}-\mathrm{OH}$ groups and calcium salts is also applicable to the development of bioactive poly(methyl methacrylate) (PMMA) bone cements. ${ }^{27), 28)}$ One of the significant problems of PMMA bone cements is loosening at the interface between bone and cement. One cause of this problem is that PMMA does not have bone-bonding ability, i.e. bioactivity. Modification of PMMA cement with 20 mass \% MPS and calcium salts such as $\mathrm{CaCl}_{2}$, calcium acetate $\left[\mathrm{Ca}\left(\mathrm{CH}_{3} \mathrm{COO}\right)_{2}\right]$, calcium hydroxide $\left[\mathrm{Ca}(\mathrm{OH})_{2}\right]$, and calcium methacrylate $\left\{\mathrm{Ca}\left[\mathrm{CH}_{2}=\right.\right.$ $\left.\mathrm{C}\left(\mathrm{CH}_{3}\right) \mathrm{COO}\right]_{2}$, , provided the cement with a apatite-forming ability in SBF. This indicated that the incorporation of $\mathrm{Si}-\mathrm{OH}$ groups and calcium salts may make the PMMA cement bioactive enough to result in a high affinity to living bone. Even though the compressive strength of the modified PMMA cements decreased after exposure to SBF, except for cement modified with $\mathrm{Ca}(\mathrm{OH})_{2}$, some modified PMMA cements showed compressive strengths near $70 \mathrm{MPa}$ after soaking in SBF for 7 days. In vivo evaluation of the PMMA cement modified with MPS and $\mathrm{Ca}\left(\mathrm{CH}_{3} \mathrm{COO}\right)_{2}$ showed osteoconduction on the modified PMMA cement after 4 weeks implantation. ${ }^{29)}$ Thus, chemical modification of PMMA using MPS and a calcium salt is useful for preparation of bioactive PMMA cement.

\section{Synthesis of functionalized biomaterials through biomimetic processes}

Bone is a well-organized composite consisting of apatite and 


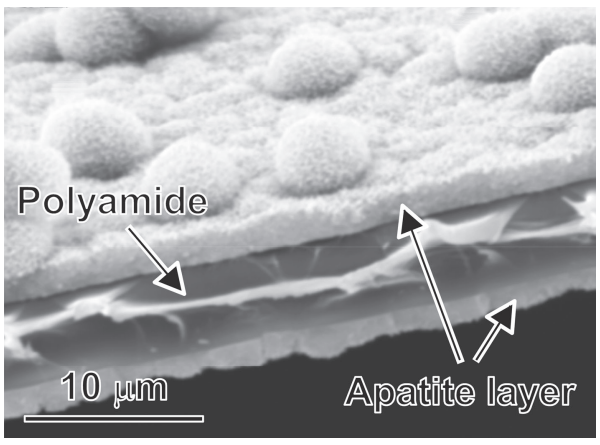

Fig. 5. Scanning electron microscopy image of bone-like apatite formed on polyamide film incorporating carboxyl groups after soaking in $1.5 \mathrm{SBF}$ for 7 days.

(a) R-silk

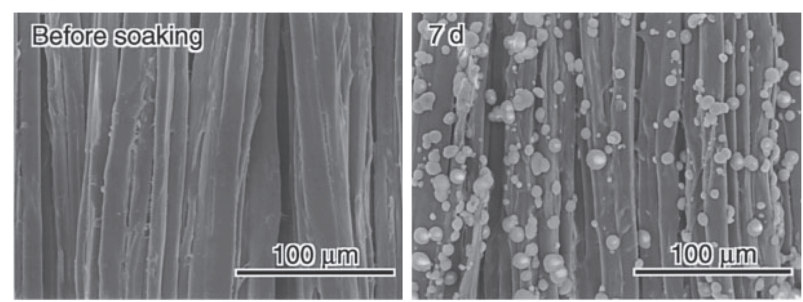

(b) N-silk

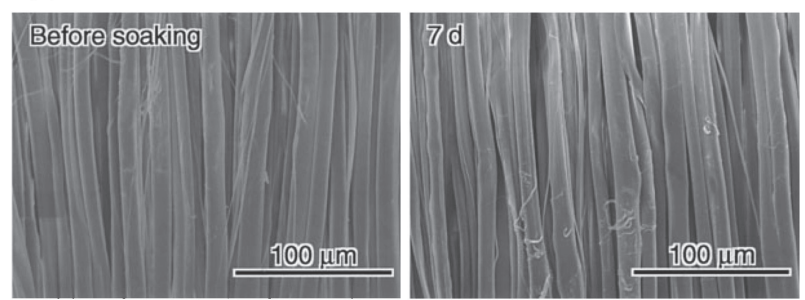

Fig. 6. Scanning electron microscopy images of the surfaces of (a) R-silk and (b) N-silk before and after soaking in $1.5 \mathrm{SBF}$ at $\mathrm{pH} 7.25$ for 7 days (abbreviated as $7 \mathrm{~d}$ ). ${ }^{34)}$

collagen. Its composite structure leads to unique mechanical properties that enable the motion of living bodies. Biomimetic processing has received much attention for the fabrication of similar composites composed of organic polymers and calcium phosphates.

The $-\mathrm{COOH}$ group is one functional group that can induce the heterogeneous nucleation of apatite in SBF. ${ }^{14), 30), 31)}$ Formation of a bone-like apatite layer has been successfully observed on a polyamide film containing $-\mathrm{COOH}$ groups and $\mathrm{CaCl}_{2}$ after exposure of the film to $1.5 \mathrm{SBF}$, which has 1.5 times the ion concentrations of SBF (Fig. 5) ${ }^{32)}$ Bone-like apatite was also formed on polyamide film incorporating sulfo $\left(-\mathrm{SO}_{3} \mathrm{H}\right)$ groups and $\mathrm{CaCl}_{2}$ in $1.5 \mathrm{SBF}^{33)}$ Hence, specific functional groups on polymer substrate were found to induce heterogeneous nucleation of apatite in $1.5 \mathrm{SBF}$, and hybridization of polymers with apatite was achieved. A similar idea proposed is the application of such an apatite coating on natural polymers such as silk fibers. The surface of raw silk (R-silk) fiber induced apatite deposition in $1.5 \mathrm{SBF}$, whereas refined silk (normal silk; N-silk) did not (Fig. 6) ${ }^{34)}$ The surface of R-silk is composed of sericin, while that of N-silk is composed of fibroin. Sericin has higher amounts of $-\mathrm{COOH}$ groups than fibroin, and thus induced apatite deposition on the R-silk surface. The formation of apatite on the R-silk was enhanced by treatment of the R-silk fiber cloth with $\mathrm{CaCl}_{2}$ solution prior to soaking in $1.5 \mathrm{SBF}$. Treatment of $\mathrm{R}-$ silk cloth by 1.0 or $5.0 \mathrm{~mol} \cdot \mathrm{dm}^{-3} \mathrm{CaCl}_{2}$ solution led to complete coverage of the surface of the silk fiber with bone-like apatite after 7 days of soaking in 1.5SBF. Sericin was found to most effectively induce the heterogeneous nucleation of apatite in $1.5 \mathrm{SBF}$ when it had a high molecular weight as well as a $\beta$ sheet structure. ${ }^{35)}$ This means that the induction of apatite nucleation may be affected not only by the number of functional groups but also by their steric structure.

\section{Fabrication of highly bioabsorbable ceramics}

Bioabsorbable ceramics gradually reduce their volume after implantation in bony defects. $\beta$-tricalcium phosphate [TCP, $\left.\mathrm{Ca}_{3}\left(\mathrm{PO}_{4}\right)_{2}\right]$ ceramics are typical materials which are bioabsorbable after implantation for bone repair. Still, control of the bioabsorbability of such materials is required when drugs are introduced into the ceramics to enhance bone regeneration. Because the solubility of $\alpha$-TCP is higher than that of $\beta$-TCP, $\alpha$ TCP ceramics yield candidate materials with high bioabsorbability for application as bone substitutes and scaffolds for tissue engineering. The fabrication of $\alpha$-TCP porous ceramics with continuous pores of approximately $10-100 \mu \mathrm{m}$ in size by a conventional sintering process using $\beta$-TCP powder and potato starch as starting materials was reported. ${ }^{36)}$ The porosity of these porous ceramics was controllable by the amount of starch, which is a pore former. This structure can be combined with polymers and drugs to provide additional functions to the materials. Coating of the framework of an $\alpha$-TCP porous body with hydroxypropylcellulose reduced its bioabsorbability, and improved its workability. ${ }^{37)}$ When drugs or osteoinductive factors were incorporated into the $\alpha$-TCP porous ceramic, a high bone regeneration ability was observed. $\alpha$-TCP porous ceramic combined with a bone morphogenetic protein-derived peptide, which promotes bone formation, showed high bone regeneration potential in a 20 -mm-long radial bone defect in rabbit. ${ }^{38)}$ These findings indicated that this $\alpha$-TCP porous ceramic may act as an appropriate scaffold in tissue defects with adequate pharmaceuticals or cells.

Controlling the fraction of $\alpha$-TCP and $\beta$-TCP in the porous ceramic gives an alternative method to adjust the bioabsorbability because the solubility of $\alpha$ - and $\beta$-TCP are different even though they have same composition. Biphasic TCP porous ceramics with various ratios of $\alpha$ - and $\beta$-phase were fabricated with addition of $\mathrm{Mg}, \mathrm{Zn}$, and $\mathrm{Fe}^{39), 40)}$ The addition of $\mathrm{Mg}$ was the most effective in decreasing the porosity and $\alpha$-phase content, allowing the preparation of a porous body consisting of $\alpha$ - and $\beta$-TCP with continuous pores ranging from $10-50 \mu \mathrm{m}$ when the $\mathrm{Mg}$ content was 0.1 mass $\%$. Investigation on in vivo behavior of the TCP porous ceramics consisting of biphasic $\alpha$ - and $\beta$-TCP $(\alpha / \beta$-TCP), in comparison with that of TCP ceramics consisting of a single $\alpha$ or $\beta$-TCP phase, revealed that the biphasic TCP porous ceramics showed intermediate absorbability and bone formation between $\alpha$-TCP and $\beta$-TCP. ${ }^{41)}$ The behavior of these TCP ceramics in the body environment was affected not only by the phase contents but also by the porosity of the ceramics. This designed bioabsorbability of the TCP ceramics is expected to provide novel biomaterials for support scaffolds in tissue engineering.

\section{Synthesis processes of calcium phosphates with controlled morphology}

Biomaterials composed of calcium phosphates have been developed for bone reconstruction, due to their high affinity to living bone. The biological affinity of calcium phosphates depends not only on their composition but also on their 
morphology. Crystal morphology is one of dominant factors affecting physiological functions. ${ }^{42)}$ Hydrothermal processing is a route allowing the fabrication of calcium phosphate crystals with unique morphology. Appropriate biological behavior was reported on porous block of HAp fabricated through hydrothermal processing. ${ }^{43)}$ To achieve further development of well-designed HAp-based materials with controlled crystal morphology, formation of HAp through hydrothermal processing should be clarified. Hence fundamental studies on formation of HAp under hydrothermal condition are required. After the investigation on HAp formation from different types of calcium phosphates, needle-like HAp crystals with various aspect ratios ranging from 11 to 45 were synthesized through a two-step hydrothermal process. ${ }^{44)}$ In this process, needle-like HAp with high aspect ratio was obtained from a mixture of two starting materials, dicalcium phosphate dihydrate (DCPD, $\left.\mathrm{CaHPO}_{4} \cdot 2 \mathrm{H}_{2} \mathrm{O}\right)$ and $\beta$-TCP. A composition of $\beta$-TCP $/ \mathrm{DCPD}=1 / 9$ (mass ratio) yielded needle-like HAp crystals after hydrothermal treatment at $160^{\circ} \mathrm{C}$. The crystals with high aspect ratio exhibited specific adsorption of proteins. ${ }^{45)}$ The amount of adsorbed bovine serum albumin (BSA) and lysozyme (LSZ), typical acidic and basic proteins, respectively, on the needle-like HAp crystals was dependent on the concentration of the phosphate buffer. When the concentration of the phosphate buffer was lower than $10 \mathrm{~mol} \cdot \mathrm{m}^{-3}$, the needle-like HAp showed specific adsorption of BSA, while irregular-shaped HAp did not show specific adsorption of proteins. Protein adsorption behavior was also detected by peak shifts in the localized surface plasmon resonance (LSPR) spectra of silver nanoparticles deposited on the HAp crystals. ${ }^{46)}$ Peak shifts in the LSPR spectra clearly corresponded to the amounts of BSA and LSZ adsorbed after exposure of the composites to protein solutions. The adsorption/desorption cycle of BSA was applied to porous bulk composites, and the reversibility of the sensing capability was confirmed. ${ }^{47}$

Crystal formation in hydrogel matrices also leads to the formation of various morphologies of calcium phosphates in aqueous media. This technique of crystal growth in a hydrogel medium is regarded as a gel-mediated process. Guidelines for controlling the crystalline phases and morphology of calcium phosphates under various conditions using $\mathrm{pH}$, calcium ion concentration, and phosphate ion concentration were reported. The resulting calcium phosphate crystalline phases varied from HAp to DCPD or dicalcium phosphate anhydrous (DCPA, $\mathrm{CaHPO}_{4}$ ) through to octacalcium phosphate [OCP, $\left.\mathrm{Ca}_{8}\left(\mathrm{HPO}_{4}\right)_{2}\left(\mathrm{PO}_{4}\right)_{4} \cdot 5 \mathrm{H}_{2} \mathrm{O}\right]$ with decreasing $\mathrm{pH}$ of the hydrogel, while they varied from OCP to HAp through to DCPD and/or DCPA with increasing phosphate ion concentration in the hydrogel. ${ }^{48), 49)}$ Figure 7 shows OCP formed in silica hydrogel under various $\mathrm{pH}$ and temperature conditions. The morphology of OCP changed from spherical to rod- or ribbon-like with increasing reaction temperature and decreasing $\mathrm{pH}$, while the morphology of HAp changed from irregular to rod-like with increasing reaction temperature and decreasing $\mathrm{pH}$. The hydrogel matrix technique is expected to allow the fabrication of organic-inorganic composites with designed calcium phosphate morphology under biomimetic conditions, to achieve novel types of biomaterials for bone repair.

\section{Summary}

The designed biomaterials derived from bioactive ceramics has been reviewed. Bone-bonding ability is governed by the formation of a bone-like apatite layer on the surface of the implanted ceramics. Based on an understanding of the chemical reactions occurring on the surface of bioactive ceramics in body
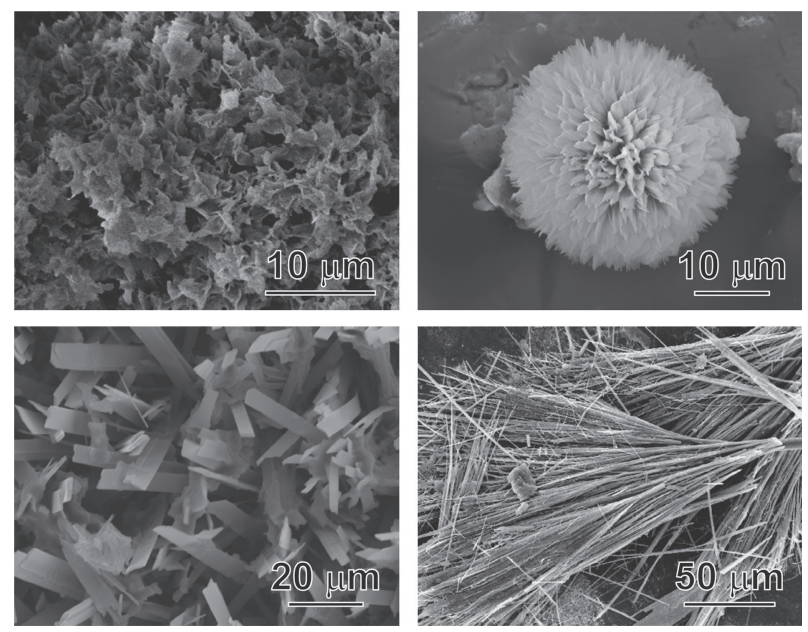

Fig. 7. Scanning electron microscopy images of octacalcium phosphate formed in hydrogel under various conditions. ${ }^{48)}$

fluid, chemical treatment of titanium-based materials was proposed for inducing bone-like apatite deposition in a body environment. The design of bioactive organic-inorganic hybrids was established from the concept of organic modification of calcium silicates. The synthesis of organic polymers with incorporated silanol $(\mathrm{Si}-\mathrm{OH})$ groups and calcium salts results in polymers with an apatite forming ability. Chemical reaction on such organic polymers in a solution mimicking body fluid allows the fabrication of composites consisting of polymer and calcium phosphates through biomimetic processing. For enhanced bone regeneration, highly absorbable calcium phosphates with a designed structure were synthesized by conventional sintering process. Techniques for the morphological control of calcium phosphates through hydrothermal processes and crystallization in hydrogel matrix were established. The designed materials described in this review are candidates for novel biomaterials able to act as a support for the reconstruction of bone tissues as well as suitable matrix for tissue regeneration.

Acknowledgments The author is deeply grateful to Prof. T. Kokubo (Chubu Univ.), Prof. A. Osaka (Okayama Univ.), Prof. M. Tanihara (Nara Inst. Sci. Tech.), Prof. M. Kawashita (Tohoku Univ.), Prof. T. Miyazaki (Kyushu Inst. Tech.), and Prof. M. Kamitakahara (Tohoku Univ.) for their support and discussions. Advisers and colleagues of the author's researches are also all very much appreciated. The works described in this review were partially supported by a Grant-in-Aid for Scientific Research (No. 22107007) on the Innovative Areas: "Fusion Materials" (Area no. 2206) from the Ministry of Education, Culture, Sports, Science and Technology (MEXT), Japan.

\section{References}

1) L. L. Hench, R. J. Splinter, W. C. Allen and T. K. Greenlee, J. Biomed. Mater. Res. Symp., 2, 117-141 (1971).

2) L. L. Hench, J. Am. Ceram. Soc., 81, 1705-1728 (1998).

3) C. Ohtsuki, H. Kushitani, T. Kokubo, S. Kotani and T. Yamamuro, J. Biomed. Mater. Res., 25, 1363-1370 (1991).

4) M. Neo, S. Kotani, Y. Fujita, T. Nakamura, T. Yamamuro, Y. Bando, C. Ohtsuki and T. Kokubo, J. Biomed. Mater. Res., 26, 255-267 (1992).

5) M. Neo, S. Kotani, T. Nakamura, T. Yamamuro, C. Ohtsuki, T. Kokubo and Y. Bando, J. Biomed. Mater. Res., 26, 1419-1432 (1992). 
6) T. Kokubo, J. Non-Cryst. Solids, 120, 138-151 (1990).

7) T. Kokubo, H. Kushitani, S. Sakka, T. Kitsugi and T. Yamamuro, J. Biomed. Mater. Res., 24, 721-734 (1990).

8) C. Ohtsuki, Y. Aoki, T. Kokubo, Y. Bando, M. Neo and T. Nakamura, J. Ceram. Soc. Japan, 103, 449-454 (1995).

9) C. Ohtsuki, T. Kokubo, K. Takatsuka and T. Yamamuro, J. Ceram. Soc. Japan, 99, 1-6 (1991).

10) C. Ohtsuki, T. Kokubo and T. Yamamuro, J. Mater. Sci.: Mater. Med., 3, 119-125 (1992).

11) C. Ohtsuki, T. Kokubo and T. Yamamuro, J. Non-Cryst. Solids, 143, 84-92 (1992).

12) P. Li, C. Ohtsuki, T. Kokubo, K. Nakanishi, N. Soga, T. Nakamura and T. Yamamuro, J. Am. Ceram. Soc., 75, 2094 2097 (1992).

13) P. Li, C. Ohtsuki, T. Kokubo, K. Nakanishi, N. Soga and K. deGroot, J. Biomed. Mater. Res., 28, 7-15 (1994).

14) M. Tanahashi and T. Matsuda, J. Biomed. Mater. Res., 34, 305315 (1997).

15) T. Miyazaki, H.-M. Kim, T. Kokubo, C. Ohtsuki and M. Ashizuka, J. Ceram. Soc. Japan, 112, S848-S852 (2004).

16) C. Ohtsuki, H. Iida, S. Hayakawa and A. Osaka, J. Biomed. Mater. Res., 35, 39-47 (1997).

17) T. Kim, M. Suzuki, C. Ohtsuki, K. Masuda, H. Tamai, E. Watanabe, A. Osaka and H. Moriya, J. Biomed. Mater. Res., Part B, 64, 19-26 (2003).

18) A. Sugino, K. Tsuru, S. Hayakawa, K. Kikuta, G. Kawachi, A. Osaka and C. Ohtsuki, J. Ceram. Soc. Japan, 117, 515-520 (2009).

19) A. Sugino, K. Uetsuki, K. Tsuru, S. Hayakawa, A. Osaka and C. Ohtsuki, Mater. Trans., 49, 428-434 (2008).

20) K. Tsuru, C. Ohtsuki, A. Osaka, T. Iwamoto and J. D. Mackenzie, J. Mater. Sci.: Mater. Med., 8, 157-161 (1997).

21) Q. Chen, N. Miyata, T. Kokubo and T. Nakamura, J. Biomed. Mater. Res., 51, 605-611 (2000).

22) N. Miyata, K. Fuke, Q. Chen, M. Kawashita, T. Kokubo and T. Nakamura, Biomaterials, 23, 3033-3040 (2002).

23) C. Ohtsuki, T. Miyazaki and M. Tanihara, Mater. Sci. Eng., C, 22, 27-34 (2002).

24) K. Hosoya, C. Ohtsuki, T. Kawai, M. Kamitakahara, S. Ogata, T. Miyazaki and M. Tanihara, J. Biomed. Mater. Res., Part A, 71A, 596-601 (2004).

25) T. Ichibouji, T. Miyazaki, E. Ishida, M. Ashizuka, A. Sugino, C. Ohtsuki and K. Kuramoto, J. Ceram. Soc. Japan, 116, 74 78 (2008).

26) M.-Y. Koh, T. Miyazaki and C. Ohtsuki, J. Biomater. Appl., 25, 581-594 (2011).

27) C. Ohtsuki, T. Miyazaki, M. Kyomoto, M. Tanihara and A. Osaka, J. Mater. Sci.: Mater. Med., 12, 895-899 (2001).

28) A. Mori, C. Ohtsuki, A. Sugino, K. Kuramoto, T. Miyazaki, M. Tanihara and A. Osaka, J. Ceram. Soc. Japan, 111, 738-742 (2003).

29) A. Sugino, C. Ohtsuki and T. Miyazaki, J. Biomater. Appl., 23, 213-228 (2008).
30) M. Kawashita, M. Nakao, M. Minoda, H.-M. Kim, T. Beppu, T. Miyamoto, T. Kokubo and T. Nakamura, Biomaterials, 24, 2477-2484 (2003).

31) T. Kokubo, M. Hanakawa, M. Kawashita, M. Minoda, T. Beppu, T. Miyamoto and T. Nakamura, J. Mater. Sci.: Mater. Med., 15, 1007-1012 (2004).

32) T. Miyazaki, C. Ohtsuki, Y. Akioka, M. Tanihara, J. Nakao, Y. Sakaguchi and S. Konagaya, J. Mater. Sci.: Mater. Med., 14, 569-574 (2003).

33) T. Kawai, C. Ohtsuki, M. Kamitakahara, T. Miyazaki, M. Tanihara, Y. Sakaguchi and S. Konagaya, Biomaterials, 25, 4529-4534 (2004).

34) A. Takeuchi, C. Ohtsuki, T. Miyazaki, H. Tanaka, M. Yamazaki and M. Tanihara, J. Biomed. Mater. Res., 65A, 283-289 (2003).

35) A. Takeuchi, C. Ohtsuki, T. Miyazaki, M. Kamitakahara, S. Ogata, M. Yamazaki, Y. Furutani, H. Kinoshita and M. Tanihara, J. R. Soc., Interface, 2, 373-378 (2005).

36) M. Kitamura, C. Ohtsuki, S. Ogata, M. Kamitakahara and M. Tanihara, Mater. Trans., 45, 983-988 (2004).

37) M. Kitamura, C. Ohtsuki, H. Iwasaki, S. Ogata, M. Tanihara and T. Miyazaki, J. Mater. Sci.: Mater. Med., 15, 1153-1158 (2004).

38) A. Saito, Y. Suzuki, M. Kitamura, S. Ogata, Y. Yoshihara, S. Masuda, C. Ohtsuki and M. Tanihara, J. Biomed. Mater. Res., 77A, 700-706 (2006).

39) M. Oishi, C. Ohtsuki, M. Kitamura, M. Kamitakahara, S. Ogata, T. Miyazaki and M. Tanihara, Phosphorus Res. Bull., 17, 95-100 (2004).

40) M. Kamitakahara, C. Ohtsuki, M. Oishi, S. Ogata, M. Tanihara and T. Miyazaki, J. Jpn. Soc. Powder Powder Metallurgy, 52, 356-359 (2005).

41) M. Kamitakahara, C. Ohtsuki, M. Oishi, S. Ogata, T. Miyazaki and M. Tanihara, Key Eng. Mater., 284-286, 281-284 (2005).

42) S. Okada, H. Ito, A. Nagai, J. Komotori and H. Imai, Acta Biomater., 6, 591-597 (2010).

43) T. Okuda, K. Ioku, I. Yonezawa, H. Minagi, Y. Gonda, G. Kawachi, M. Kamitakahara, Y. Shibata, H. Murayama, H. Kurosawa and T. Ikeda, Biomaterials, 29, 2719-2778 (2008).

44) T. Watanabe, G. Kawachi, M. Kamitakahara, K. Kikuta and C. Ohtsuki, J. Ceram. Soc. Japan, 117, 759-764 (2009).

45) G. Kawachi, T. Watanabe, S. Ogata, M. Kamitakahara and C. Ohtsuki, J. Ceram. Soc. Japan, 117, 847-850 (2009).

46) Y. Ichikawa, S. Ogata, T. Torimoto, G. Kawachi, K. Kikuta and C. Ohtsuki, J. Ceram. Soc. Japan, 117, 294-298 (2009).

47) C. Ohtsuki, Y. Ichikawa, H. Shibata, G. Kawachi, T. Torimoto and S. Ogata, J. Mater. Sci.: Mater. Med., 21, 1225-1232 (2010).

48) T. Yokoi, M. Kawashita, G. Kawachi, K. Kikuta and C. Ohtsuki, J. Mater. Res., 24, 2154-2160 (2009).

49) T. Yokoi, M. Kawashita, K. Kikuta and C. Ohtsuki, Mater. Sci. Eng., C, 30, 154-159 (2010).

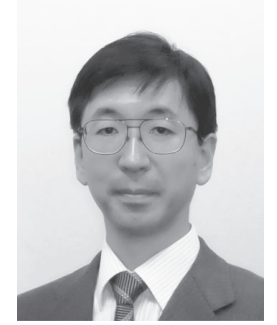

Chikara Ohtsuki is a professor at the Graduate School of Engineering, Nagoya University. He received his Ph.D. in Science at Kyoto University in 1992. After a year as an assistant professor at Kyoto University, he joined the Faculty of Engineering, Okayama University, Japan in 1993 as a lecturer where he advanced to associate professor in 1996. He joined the Graduate School of Materials Science, Nara Institute of Science and Technology in 1998 as an associate professor. In 2006, he joined the Graduate School of Engineering, Nagoya University as a professor. His research interests include the synthesis of biomaterials through biomimetic processes, reaction of bioactive ceramics with body fluid, design of novel biomaterials derived from ceramic materials, and synthesis of composite materials for biomedical applications. 